\title{
Plausibilidade arGumentativa, LÓGICA DE REVISÃO DE CRENÇAS E RESISTÊNCIA RACIONAL A ARGUMENTOS COGENTES
}

\author{
PLAUSIBILITY, LOGIC OF REVISION OF BELIEFS AND RATIONAL RESISTANCE \\ TO COGENT ARGUMENTS
}

\author{
FERNANDO FURTADO 1 \\ Universidade de Lisboa - Portugal \\ fernandofurtado@campus.ul.pt
}

\begin{abstract}
RESUMO: Este artigo se trata da busca por critérios que nos digam sob que circunstâncias estamos obrigados a refutar ou aceitar a conclusões de argumentos. Na primeira parte deste trabalho argumento contra ideia comumente aceita que perante um argumento cogente estamos obrigados a aceitá-lo ou a refutar a sua conclusão. Dois conceitos particulares de cogência serão estudados de perto aqui: o conceito de Adler e o de Murcho. Argumentarei que a cogência é um conceito supérfluo para regular a prática argumentativa e que o conceito de plausibilidade argumentativa que será desenvolvido aqui é suficiente para regular a prática argumentativa. Na segunda parte, à luz dos desenvolvimentos da lógica da revisão de crenças, apresento as regras para revisão de crenças via argumentos e como essas regras, juntamente com o conceito de plausibilidade argumentativa, são suficientes para regular a prática da argumentação.
\end{abstract}

PALAVRAS-CHAVE: Plausibilidade argumentativa. Cogência. Argumentação. Revisão de crenças.

ABSTRACT: This paper aims to find criteria to tell us in which circumstances we are obliged to reject or accept the conclusion of arguments. First, I argue against the common idea according to which, when one is faced with a cogent argument, one is obliged to accept or reject its conclusion. Two particular different concepts of cogency will be studied: Adler's and Murcho's. I argue that cogency is a superfluous notion for regulating argumentative practice and also that the concept of argumentative plausibility, as it will be developed here, is sufficient to regulate the argumentative practice; we can thus reject the metaphysical aspects of cogency without risking the epistemic virtue of argumentative practice. Second, I present rules for the revision of beliefs by arguments and how these rules together with the concept of argumentative plausibility are sufficient to regulate the practice of argumentation.

KEYWORDS: Argumentative plausibility. Cogency. Argumentation. Belief revision.

\footnotetext{
${ }^{1}$ Doutorando pelo Centro de Filosofia da Faculdade de Letras da Universidade de Lisboa (LanCog Group). Bolsista de Doutorado Pleno no Exterior pela CAPES.
} 


\section{INIRODUÇ̃̃O}

Talvez já tenha lhe ocorrido de estar perante um argumento que fosse incapaz de refutá-lo ou de aceitar a sua conclusão. Perante o argumento de um especialista, um corretor de ações, por exemplo, é comum sermos incapazes de refutar seu argumento. Não conhecemos a área - muitas vezes mal compreendemos o que está em causa - e, por isso, podemos ser incapazes de refutar o argumento. Nestas circunstâncias aceitamos ou rejeitamos conclusões de argumentos segundo normas muito similares às que regulam o testemunho e não nos sentimos desconfortáveis - racionalmente - caso não aceitemos a conclusão do argumento. Um caso mais complicado, todavia, acontece quando o argumentador e seu interlocutor estão em situação de paridade epistêmica. Quando há paridade epistêmica e estamos perante um argumento que reconhecemos ser cogente e não somos capazes nem de refutar o argumento nem de aceitar a conclusão, ficamos em uma situação aparentemente irracional e sentimo-nos desconfortáveis com isso. Considerando casos de paridade epistêmica apenas, será que haverão circunstâncias sob as quais seja racional rejeitar a conclusão de um argumento que o agente em causa reconhece a sua cogência e seja incapaz de refutá-lo? Esta circunstância particular será trabalhada ao longo de todo este artigo. Uma célebre passagem de David Hume acerca dos argumentos de Berkeley ilustra bem essa situação:

[...] todos seus argumentos, embora visem a outro objetivo, são, na realidade, meramente céticos, o que fica claro ao se observar que não admitem nenhuma resposta e não produzem nenhuma convicção. Seu único efeito e causar aquela perplexidade, indecisão e embaraço momentâneos que são o resultado do ceticismo (HUME, 2004, sec. XII, Parte I, nota 1, p. 210).

Para Hume os argumentos de Berkeley são típicos casos de argumentos que não se pode refutar ou aceitar. Ao longo deste artigo vou procurar formular critérios que digam sob quais circunstâncias é racionalmente legítimo nem refutar nem aceitar a conclusão de um argumento cogente e, ao mesmo tempo, discutir as características de argumentos perante aos quais parece legítimo agir dessa maneira.

\section{O PROBLEMA: FORMULAÇÃO FORMAL}

Prem. 1. (Arg. Cogente) $\rightarrow \square($ Refutar $\vee$ Aceitar $)$

Prem. 2. $\neg \diamond$ (Refutar $\vee$ Aceitar)

PaD. 3. $\square($ Refutar $\vee$ Aceitar $) \rightarrow \diamond($ Refutar $\vee$ Aceitar $)$

Sup. 4. (Arg. Cogente)

$2,3 \quad 5 . \neg \square($ Refutar v Aceitar) 2, 3 (MT)
1,2,3 6. ᄀ (Arg. Cogente)
5,1 (MT) 


\section{1,2,3,4 7. (Arg. Cogente) $\wedge \neg($ Arg. Cogente)}

$4,6(\mathrm{I} \wedge)$

Nesta demonstração a premissa 1 é a formulação da norma que parece regular a argumentação; perante um argumento cogente é epistemicamente obrigatório ( $\square$ ) refutar o argumento ou aceitar a conclusão a que ele conduz. 2 é a premissa que representa os casos em que não é epistemicamente possível $(\diamond)$ refutar o argumento ou aceitar a conclusão a que ele conduz. 3 é aplicação de um princípio inspirado no Princípio Axioma de D (PaD); se algo é epistemicamente obrigatório, é epistemicamente possível $(\square \mathrm{P} \rightarrow \diamond \mathrm{P})$. A ideia deste princípio é que só pode ser epistemicamente obrigatório aquilo que é epistemicamente possível. Se algo não é epistemicamente possível, não é epistemicamente obrigatório. Com essas premissas chegamos a conclusão em 7 , recorrendo apenas a regra de inferência Modus Tollens, que o argumento cogente que supomos em 4 é cogente e não cogente.

Três são as soluções possíveis para o problema. A primeira, rejeitar (PaD). Esta solução não me parece particularmente plausível, pois para rejeitar (PaD) temos que admitir que coisas epistemicamente impossíveis sejam exigidas de um agente para que este seja considerado racional.

A segunda possibilidade é rejeitar a condicional de 1 afirmando que perante um argumento cogente não estamos epistemicamente obrigados a refutar o argumento ou a aceitar a sua conclusão. Esta solução é mais plausível que a primeira, porém tem o desconforto de introduzir uma indeterminação na identificação dos casos em que estamos ou não obrigados a refutar ou aceitar. Isso pode comprometer a virtude epistêmica da prática argumentativa, porque a condicional tomada como norma epistêmica que guia argumentação é falsa. Parece que para mantermos a virtude da prática argumentativa, temos que seguir determinadas normas reguladoras dessa prática. A cogência dos argumentos é um critério relativamente claro e determinante para dizer perante quais argumentos estamos obrigados a refutar ou aceitar a conclusão a que o argumento conduz, negar a condicional significa perder este critério e, por consequência, introduzir indeterminação nas normas que conduzem a argumentação epistemicamente virtuosa. Portanto, pelo menos à partida, é mais interessante manter a condicional e tentar dar conta dos argumentos cogentes que parecem não nos obrigar a refutar ou aceitar de outra forma.

Terceira, atacar o conceito de cogência argumentando que, como formulado habitualmente, é insuficiente para dizer quais são as características necessárias para um argumento ser bom ou mau. Assim, a condicional - norma epistêmica da argumentação - é mantida e reformulamos sua antecedente. Esta é a solução que vou propor neste artigo. Este artigo ataca o conceito de cogência por duas vias: por um lado, tenta mostrar que critérios mais fortes e precisos que a cogência devem ser formulados para manter a condicional do problema - a cogência é

${ }^{2}$ É fácil pensar em casos nos quais seja epistemicamente impossível refutar ou aceitar (o caso do corretor de seguros, por exemplo), mas lembre-se que os casos mais importantes aqui são aqueles onde os agentes envolvidos estão em situação de paridade epistêmica. 
insuficiente -, por outro, argumenta que os aspectos metafísicos do conceito de cogência são irrelevantes para dizer sob quais circunstâncias estamos ou não obrigados a refutar ou aceitar - a cogência não é necessária.

Outra possibilidade de solucionar (ou dissolver) o problema é negar que ele de fato exista. Para tanto rejeita-se a premissa 2. argumentando que não há casos onde seja epistemicamente impossível refutar o argumento ou aceitar a conclusão. Sempre que isso acontece o agente em causa está desrespeitando uma norma epistêmica e, portanto, sendo irracional. Esta última possibilidade não será considerada neste artigo.

\section{O ARGUMENTO COGENIE}

Vale a pena antes de qualquer coisa tratar mais detalhadamente do conceito de cogência. O que é cogência? O que é um argumento cogente? Que características um argumento tem de apresentar para ser cogente? O conceito de cogência ainda está bem longe de se ver estabelecido. A partir de agora vou tratar de dois deles.

O primeiro conceito de cogência é o que Adler apresenta de passagem ainda na introdução do seu artigo.

Ao responder à apresentação de um argumento, você deve ou refutá-lo ou aceitar a sua conclusão (como verdadeira), supondo que você reconheça a congência do argumento. Por uma questão de brevidade, vamos entender congência abrangendo três elementos: solidez, premissas que não são petição de princípio e relação apropriada entre premissas e conclusão, dependendo da natureza do argumento (ADLER, 2009, p. 339). ${ }^{3}$

São três as características a se destacar na passagem: as premissas devem ser sólidas - aspecto metafísico -, não pode ser uma petição de princípio - aspecto epistêmico - e deve apresentar relação formal apropriada entre premissas e conclusão dependendo da natureza do argumento - aspecto lógico. Com essa abordagem Adler pretende evitar que argumentos cogentes tenham premissas falsas - exigindo solidez ${ }^{4}$-, sejam argumentos circulares - exigindo que os argumentos não sejam petição de princípio - e, por último, sejam argumentos inválidos ou fracos - exigindo relação formal apropriada entre premissas e conclusão. Por essa interpretação da passagem, cogência tem um aspecto metafísico, um aspecto epistêmico e um aspecto lógico. Com esta caracterização do conceito de cogência ele consegue evitar os argumentos circulares como o seguinte:

\footnotetext{
3 Tradução de responsabilidade deste autor diretamente do original em língua inglesa.

4 "Solidez" foi a palavra escolhida para traduzir "soundness". Embora "soundness" seja frequentemente traduzida em outros contextos por "correção" ou "corretude", a opção aqui por "solidez" torna a tradução uniforme com o uso que aparece na literatura sobre o assunto em língua portuguesa. Veja, por exemplo, MURCHO, 2006.
} 
A neve é branca.

Logo, a neve é branca.

Certamente este exemplo se trata de um argumento válido (ou de um argumento que apresenta relação formal apropriada entre premissas e conclusão) e é sólido; a premissa $A$ neve é branca é verdadeira. O problema é que o argumento é circular. Mas por que os argumentos circulares são maus?

Em resposta a última pergunta Desidério Murcho (MURCHO, 2006, p. 113129) sugere que apenas os aspectos lógicos e metafísicos dos argumentos não podem explicar qual o problema dos argumentos circulares e que, para tanto, devemos dar atenção aos aspectos epistêmicos da argumentação em busca de respostas ao problema. A sugestão é a noção de plausibilidade relativa entre premissas e conclusão. Além da solidez, um argumento cogente precisa ter premissas mais plausíveis que a conclusão. A plausibilidade é um conceito epistêmico abrangente que dá conta dos argumentos circulares, assim como a restrição aos casos de petição de princípio, e, portanto, tem justificativa epistêmica para ser componente do conceito de cogência.

O conceito de cogência que resulta daqui é o seguinte:

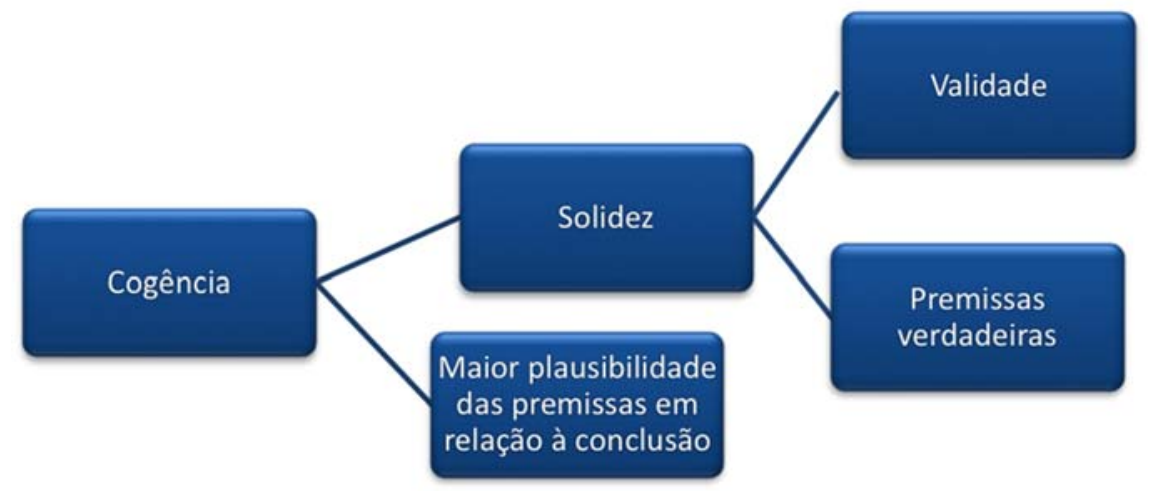

Figura 1

Conforme o gráfico o conceito de cogência 5 tem duas características importantes: a solidez e a maior plausibilidade das premissas em relação à conclusão.

Solidez: um argumento é sólido se, e somente se, é válido e tem premissas verdadeiras.

Validade: um argumento é válido se, e somente se, é impossível (em argumentos dedutivos) ou muito improvável (em argumentos indutivos) que as premissas sejam verdadeiras e a conclusão falsa.

\footnotetext{
${ }^{5}$ Em "Epistemologia da Argumentação" no lugar da expressão "argumento cogente" Murcho usa as expressões "argumento forte" ou "argumento bom". Porém, penso que podemos encarar o conceito da Figura 1 como o conceito de cogência sem que isto resulte em problemas de interpretação.
} 
A plausibilidade é relativa aos agentes cognitivos. É o quanto uma proposição parece verdadeira para um agente. O que faz com que uma premissa possa ser plausível para uma pessoa e não o ser para outra e, por consequência, que um argumento possa ser cogente para uma pessoa e não o ser para outra. Essa cláusula evita, como disse anteriormente, a petição de princípios que Adler previa e introduz o agente e suas crenças prévias no centro do conceito de cogência. Um conceito de cogência que leva em conta os agentes cognitivos que argumentam aproxima o conceito daquilo que ele pretende esclarecer: a argumentação. Assim como o conceito de cogência de Adler, o de Murcho apresenta um aspecto metafísico - o argumento deve ter premissas verdadeiras -, um aspecto lógico - o argumento deve ser válido - e um aspecto epistêmico - o argumento deve ter premissas mais plausíveis que a conclusão. Talvez a vantagem dessa formulação, comparada a de Adler, seja a clareza e precisão com que os componentes do conceito de cogência são definidos, resultando assim, num conceito de cogência também mais claro e preciso.

Um modo simplificado de formular o famoso argumento cético apresentado por Hilary Putnam (PUTNAM, 1981, p. 1-22) que cai sob os dois conceitos de cogência e que tipicamente não somos capazes de aceitar a sua conclusão é o seguinte:

\begin{tabular}{ll}
\hline $\begin{array}{l}\text { Mais } \\
\text { Plausiveis } \\
\text { (Premissas) }\end{array}$ & $\begin{array}{l}\text { Não sei se não sou um cérebro numa } \\
\text { cuba. }\end{array}$ \\
\cline { 2 - 2 } & $\begin{array}{l}\text { Se não sei se não sou um cérebro numa } \\
\text { cuba, então não sei se tenho uma mão. }\end{array}$ \\
\cline { 2 - 2 } $\begin{array}{l}\text { Menos } \\
\text { plausível } \\
\text { (Conclusão) }\end{array}$ & Logo, não sei se tenho uma mão. \\
\hline
\end{tabular}

Este exemplo cai sob o conceito de cogência tal como formulado e é um caso, assim como outros argumentos céticos, que estamos perante um argumento que não somos capazes de refutar, vemos que o argumento é cogente - certamente as premissas são mais plausíveis que a conclusão - e não somos capazes de aceitar a conclusão a que o argumento conduz.

Dois elementos metafísicos presentes na noção de cogência apresentada são excessivos para as finalidades deste artigo e pretendo evitá-los. Ambos aparecem no conceito de solidez. A formulação do conceito de cogência que preciso neste artigo segue o seguinte princípio: um argumento cogente é um motivo razoável para reformar o conjunto de crenças de um agente, se este for incapaz de refutá-lo. Desse modo, passarei a partir de agora a usar o conceito de plausibilidade argumentativa (P.A.), conforme a seguinte definição:

Validade $^{(C)}$ : o agente cognitivo acredita na validade do argumento.

$\operatorname{Verdade}^{(C)}$ : o agente cognitivo acredita na verdade das premissas. 
Estas duas reformulações forçam a reconsideração do conceito de solidez para a solidez ${ }^{(F)}$ e, por sua vez, o de cogência para plausibilidade argumentativa.

Estas modificações resultam no conceito de plausibilidade argumentativa como vemos no diagrama abaixo:

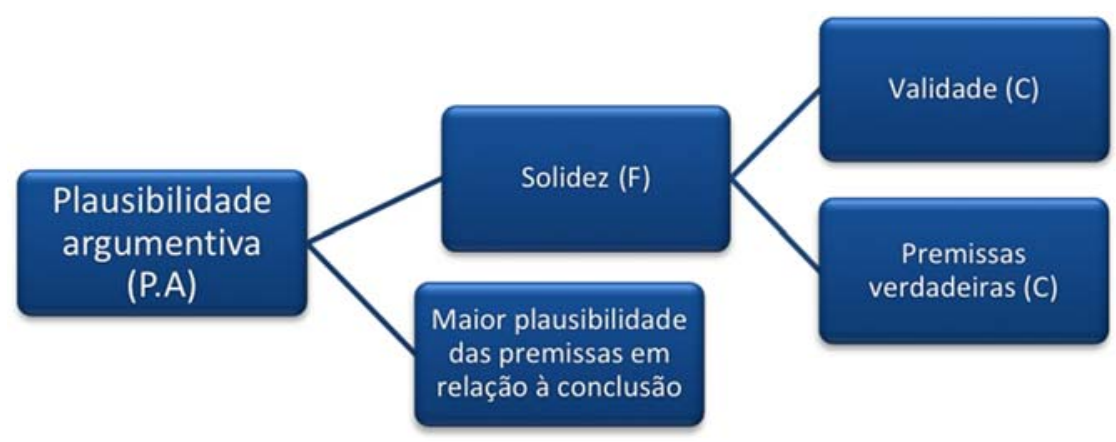

Figura 2

O conceito de plausibilidade argumentativa é análogo ao conceito de cogência, porém, é formulado sem os aspectos metafísicos desse conceito. Portanto, o conceito relevante para este artigo a partir de agora é o conceito puramente epistêmico de plausibilidade argumentativa que não se compromete com os aspectos metafísicos do conceito de cogência.

\section{SOLUÇÃO DO PROBLEMA}

Nesta seção apresento a parte mais positiva deste artigo. Aqui vou propor uma reconsideração do conceito de plausibilidade argumentativa (P.A.) formulado na seção 2. A solução que vou propor é adequar o conceito de modo a evitar o problema e preservar a condicional: se estamos perante um argumento cogente, então temos a obrigação epistêmica de refutar ou aceitar o argumento. Se a solução funcionar, tem a vantagem de manter relativamente clara a norma epistêmica que preserva a virtude da argumentação. Evitamos assim, abrir possibilidade para suspensões ilegítimas de juízo, dado que refutar ou aceitar são as únicas possibilidades legítimas perante argumentos cogentes.

É importante dizer que reconsideração do conceito P.A. que será apresentada agora é apenas parcial. Apenas nos casos onde a conclusão do argumento entrar em conflito com crenças prévias do agente relevante, as regras da P.A. serão as que apresentarei a partir de agora. Nos casos onde isso não ocorre, ou seja, onde a conclusão a que o argumento conduz não entra em conflito com o conjunto prévio de crenças do agente relevante, a P.A. é adequada para regular esses casos. Por outras palavras, nos casos em que a conclusão do argumento não entra em conflito com crenças prévias do agente relevante, é legítimo reformar o conjunto de crenças ou refutar o argumento sob as regras de P.A. Nos casos em que a conclusão do argumento entra em conflito com crenças prévias do agente relevante, a reforma do conjunto de crenças deve proceder segundo as regras que serão formuladas a seguir. 


\subsection{LÓGICA DE REVISÃO DE CRENÇAS}

Antes de prosseguirmos com a solução ao problema que irei avançar, alguns aspectos importantes da lógica da revisão de crenças que serão usados aqui devem ser explicados. A lógica da revisão de crença é uma área interdisciplinar particularmente importante para ciência da computação e para a filosofia. As bases dessa disciplina começaram a se erguer no início dos anos setenta, porém apenas após os trabalhos de Carlos Alchourrón, Peter Gärdenfors e David Makinson resultarem no chamado "modelo AGM" (ALCHOURRON, GÄRDENFORS, MAKINSON, 1985, p. 510-530), a discussão entorno da lógica da dinâmica da revisão de crenças (como por vezes é chamada) se tornou mais evidente e passou a ocupar mais espaço nos periódicos especializados. Nesta subseção apresento alguns postulados, conceitos e resultados da lógica da revisão de crenças que serão usados como ferramentas para solucionar o problema central deste artigo. Limitome àqueles aspectos menos controversos e mais intuitivos dessa lógica. Sendo assim, não entrarei em detalhes técnicos de pormenor que possam comprometer a compreensão do problema central.

\subsubsection{A LINGUAGEM FORMAL}

Na lógica da revisão de crenças um estado de crenças (ou banco de dados) é representado por um conjunto logicamente fechado de frases e é chamado de conjunto de crenças. Desse modo, as crenças são representadas por frases em uma linguagem formal. Portanto, a linguagem que vamos precisar é a linguagem proposicional clássica com todos os operadores verofuncionais. ${ }^{6}$ As variáveis e os operadores são, assim, os mesmos da lógica clássica, apenas reservarei letras minúsculas $(p, q, r \ldots)$ para representar frases particulares e letras maiúsculas para conjuntos de frases. Usarei a notação $K \vdash \alpha$, se $K$ implica logicamente $\alpha$, e $\operatorname{Cn}(K)^{7}$ para todas as implicações lógicas de $K$. Para qualquer conjunto $K$ de frases, $C n(K)$ é conjunto de todas as frases que são consequência lógica de $K$. Cn é, então, o operador de consequência lógica. Por $C n$ devemos compreender que se $p$ é derivada de $A$ recorrendo às regras da lógica proposicional clássica apenas, então $p \in C n(A)$. Desse modo, $A$ é um conjunto de crenças se, e somente se, $A=C n(A)$. Um conjunto de crenças é um conjunto de fórmulas logicamente fechado, ou seja, se $K \vdash \alpha$, então $\left.\alpha \in K^{8}{ }^{(} \perp\right)$ denota uma contradição arbitrária e (T) uma tautologia arbitrária.

\footnotetext{
6 As palavras "frase" e "proposição" como são usadas aqui não tem a intenção de comprometer este autor (ou o seu leitor) com qualquer posição filosoficamente relevante acerca das entidades às quais essas palavras referem. Sendo assim, o leitor pode subir livremente a palavra "frase" por "proposição" e vice-versa onde quer que elas ocorram de acordo com sua preferência particular.

${ }^{7}$ Cn é operador de consequência lógica de Tarski que é definido de modo a satisfazer às seguintes condições: Inclusão: $A \subseteq C n(A)$, Monotonicidade: Se $A \subseteq B$, então $C n(A) \subseteq C n(B)$ e Idempotência: $\operatorname{Cn}(A)=\operatorname{Cn}(\operatorname{Cn}(A))$.

${ }^{8}$ É comum assumir que o conjunto de crenças de um agente é fechado sob a consequência lógica, ou seja, cada crença que se segue logicamente desse conjunto já é um membro dele. Essa abordagem é claramente uma idealização irrealista, uma vez que significa que os agentes cognitivos
} 


\subsubsection{OPERAÇÕES DE MUDANÇA NO MODELO AGM}

Um dos princípios fundamentais da teoria da revisão de crenças é o Princípio da Mudança Mínima. Segundo este princípio, qualquer mudança que venha ocorrer num conjunto de crenças prévio deve ser a mínima possível e, portanto, deve deixar como resto a maior quantidade de informação possível.

No modelo $A G M$ há três tipos de operações básicas para mudanças em estados de crenças que, quando realizadas, devem satisfazer ao Princípio da Mudança Mínima: contração, expansão e revisão.

Contração: uma crença específica $p$ é removida de um conjunto de crenças $K$, isto é, um conjunto de crenças $K$ é substituído por $K-p$, que é um subconjunto de $K$ que não contém $p$.

Expansão: uma crença $p$ é adicionada a $K$ e nada é retirado, isto é, $K$ é substituído pelo conjunto $K+p$ que é o menor conjunto logicamente fechado que contém $K$ e $p$.

Revisão: uma crença $p$ é adicionada a $K$ e ao mesmo tempo outras crenças são removidas, caso necessário, resultando num conjunto consistente $K^{*} p .{ }^{?}$

No modelo AGM a revisão pode ser reduzida à contração através das chamadas Identidade Levi e Identidade Harper. Levi e Harper identificaram os casos de contração e revisão. Provaram que as operações de contração são operações de revisão e vice-versa, como as seguintes identidades:

1) Identidade Levi: $K^{*} \alpha=(K-\neg \alpha)+\alpha$.

2) Identidade Harper: $K-\alpha=K \cap\left(K^{*} \neg \alpha\right)$.

Exemplos informais intuitivos para os casos de expansão e revisão vêm à mente com facilidade:

Expansão $(K+p)$ : suponhamos que Wesley está em casa numa tarde de domingo aguardando para ver o jogo de futebol que vai passar na TV. Porém, ele não faz ideia em qual dos vários canais de esportes que tem em sua TV por assinatura o jogo vai passar. Alguns minutos depois alguém chega à sala e diz que o jogo do Vasco - exatamente o que ele queria ver - vai passar no Canal 39. Nesse caso, Wesley apenas adiciona a nova crença $p$ - o jogo do Vasco vai passar no Canal 39 - ao seu conjunto prévio de crenças $K$.

são considerados logicamente omniscientes. No entanto, essa idealização é útil, dado que simplifica o trato lógico e possibilita um tratamento formal da dinâmica de crença. Isaac Levi (1991) tentou esclarecer a natureza dessa idealização, argumentando que um conjunto de crenças consiste nas crenças com as quais um agente está comprometido, não apenas nas crenças que ele atualmente acredita. De acordo com Levi, estamos comprometidos a acreditar em todas as consequências lógicas de nossas crenças. A abordagem de Levi torna essa ideia mais plausível, mas certamente pode ser posta em causa.

${ }^{9}$ Sempre lembrando que quando adicionamos ou retiramos uma frase $p$ de um conjunto de crenças $K$, por estarmos na verdade comprometidos com $C n(p)$, a mesma operação deve ser feita com as consequências lógicas de $p$. 
Revisão ( $K^{*} p$ ): numa situação ligeiramente diferente, suponhamos agora que Wesley tinha em seu conjunto de crenças $K$, a crença $q$ - o jogo do Vasco passará no Canal 38. Nesta circunstância a nova crença $p$ - o jogo do Vasco passará no Canal 39 - é inconsistente com $K$. Portanto, uma operação de revisão deve ser feita para acomodar a nova crença $p$. Esta operação deve resultar em um conjunto $K^{\prime}$ consistente de crença apenas pela adição da nova crença $p$ e exclusão das crenças inconsistentes com ela.

A expansão é um caso que não levanta grandes problemas nem para a lógica da revisão de crenças nem para a investigação que é desenvolvida neste artigo. A revisão e a contração, ao contrário, são os casos mais problemáticos e veremos em pormenor agora. Veremos dois casos particulares de contração: a contração parcial e a contração por base consolidada; e um caso de revisão: a revisão parcial. ${ }^{10}$

\subsubsection{CONIRAÇÃO PARCIAL}

Na operação de contração parcial, a contração de $K$ pela crença $p$ resulta em um subconjunto de inclusão maximal de $K$ que não implique $p$. A exigência que o resultado da contração seja um subconjunto de inclusão maximal de $K$ evita que elementos de $K$ sejam desnecessariamente removidos. Pode haver mais de um subconjunto de inclusão maximal de $K$ que não implique $p$. Neste caso o conjunto resto $K \perp p$ será o conjunto de todos os subconjuntos de inclusão maximal de $K$ que não implicam $p$. Cada elemento de $K \perp p$ é chamado de "resto". ${ }^{11}$

Desse modo, uma operação de contração $K-p$ será um dos restos se ela minimiza a perda de informação. A contração parcial é a interseção de alguns dos conjuntos resto. O operador de contração parcial envolve uma função de seleção que escolhe os melhores elementos de $K \perp p$. De modo mais preciso, uma função de seleção de $K$ é uma função $\gamma$ tal que, se $K \perp p$ for vazio, então $\gamma(K \perp p)$ é um subconjunto de $K \perp p$ que não é vazio. Num caso limite onde $K \perp p$ é vazio, $\gamma(K \perp p)$ é, por definição, igual ao conjunto $\{K\}$.

O resultado da contração parcial é igual a interseção dos conjuntos selecionados que são elementos de $K \perp p$, em termos mais formais, $K-p=\bigcap \gamma(K \perp p)$.

O caso especial onde a função de seleção $\gamma(K \perp p)$ tem como saída apenas um elemento de $K \perp p$ é chamado de contração por escolha máxima. (Ex.: caso em que $p$ é uma verdade lógica). E o caso onde a função de seleção tem como saída todos os elementos de $K \perp p$ é chamado de contração completa. ${ }^{12}$ (Ex.: caso em que $p$ é uma contradição).

\footnotetext{
${ }^{10}$ Essas expressões foram escolhidas para traduzir para o português as seguintes expressões da língua inglesa: "partial meet contraction" e "entrenchment-based contraction" e "partial meet revision".

11 "Resto" é a tradução para a palavra "remainder".

12 "Contração por escolha máxima" traduz "maxichoice contraction". E "contração completa” traduz "full meet contraction".
} 
Uma contração parcial de um conjunto de crenças $K$ deve satisfazer aos seis postulados básicos do modelo AGM:

1) Fechamento: $K-p=\operatorname{Cn}(K-p)$.

Quando um conjunto de crenças $K$ é contraído. O resultado da contração tem de ser logicamente fechado.

2) Sucesso: se $p \notin C n(\varnothing)$, então $p \notin C n(K-p)$.

A contração tem de ser bem-sucedida, ou seja, na contração $K-p, K$ não pode implicar $p$. O postulado do sucesso deve ser condicionado aos casos onde $p$ não é uma verdade lógica, ou seja, $p \notin C n(\varnothing)$.

3) Inclusão: $K-p \subseteq K$.

$K-p$ tem de ser um subconjunto de $K$.

4) Vacuidade: se $p \notin C n(K)$, então $K-p=K$.

Se a crença a ser contraída $p$ não pertence ao conjunto original $K$, então a operação não envolve mudança. Neste caso, a operação é vácua.

5) Extensionalidade: se $C n(p)=C n(q)$, então $K-p=K-q$.

A extensionalidade garante que a lógica da contração permita que frases logicamente equivalentes possam ser substituídas umas pelas outras livremente.

6) Recuperação: $K \subseteq(K-p)+p$.

Pela recuperação, tudo deve ser recuperado, depois da retirada de $p$, apenas pela adição (por expansão) de $p$.

Um dos resultados mais importantes do modelo AGM é a demonstração do teorema da contração parcial. Segundo esse teorema, um operador (-) é um operador de contração parcial, para um conjunto de crenças $K$, se, e somente se, satisfaz aos postulados de 1) à 6).

A função de seleção escolhe o melhor (ou o que mais vale a pena reter) de todos os membros de $(K \perp p)$. Porém a definição de função seleção é muito geral e imprecisa e permite variados padrões de seleção. Uma função de seleção bem ordenada deve sempre escolher o melhor membro do conjunto resto por uma preferência relacional. Uma função de seleção $\gamma$ de um conjunto de crenças $K$ é relacional se, e somente se, há uma relação binária $\mathbf{R}$ tal que, para toda frase $p$, se $(K \perp p)$ não é vazio, então $\gamma(K \perp p)=\{B \in(K \perp p) \mid C \mathrm{R} B$ para todo $C \in K \perp p\}$. E, se $\mathbf{R}$ é transitiva, então y é a contração parcial que dá origem a ela são transitivamente relacionais. ${ }^{13}$

Com essa caracterização da contração parcial transitivamente relacional, postulados adicionais são necessários para regular os casos de contração por conjunções. São adicionados aos postulados básicos do modelo AGM, os

${ }^{13} \mathrm{R}$ é uma relação transitiva se, e só se, para todo $\mathrm{x}, \mathrm{y} z$, se xRy e yRz, então xRz. 
postulados suplementares de Gärdenfors: a inclusão conjuntiva e a sobreposição conjuntiva.

7) Inclusão conjuntiva: Se $p \notin K-(p \wedge q)$, então $K-(p \wedge q) \subseteq K-p$.

A inclusão conjuntiva garante que tudo que é retido em $K-(p \wedge q)$ é retido também em $\mathrm{K}-\mathrm{p}$.

8) Sobreposição conjuntiva: $(K-p) \cap(K-q) \subseteq K-(p \wedge q)$.

Outro postulado bastante plausível da contração por conjunções é que se a operação da contração de $p(K-p)$ e a contração de $q(K-q)$ for avançada, então a contração de $p$ e $q(K-(p \wedge q))$ também deve ser legítima.

Um operador - de $K$ é contração parcial transitivamente relacional se, e somente se, satisfaz aos seis postulados básicos do modelo AGM e aos postulados suplementares de Gärdenfors. Em outras palavras, um operador - de $K$ é uma contração parcial transitivamente relacional se, e somente se, satisfaz aos postulados de 1) à 8).

\subsubsection{CONIRAÇÃO POR BASE CONSOLIDADA}

A contração por base consolidada é a noção da lógica da revisão de crenças que é mais importante para os propósitos deste artigo. A ideia que está por trás desse modelo é que um agente epistêmico, quando posto em uma situação que se encontra obrigado a contrair seu conjunto de crenças (abandonar crenças anteriores), deve abandonar as crenças que tem menor poder explicativo ou são menos relevantes para investigação ou deliberação ou tem menor valor epistêmico. A ideia é que em nosso conjunto de crenças há crenças mais básicas que outras. Dizer que "uma crença $\alpha$ está mais consolidada que outra crença $\beta$ " ou, como é mais comum em filosofia, dizer que "uma crença $\alpha$ é mais básica que outra crença $\beta$ " é o mesmo que dizer que " $\alpha$ tem maior poder explicativo, é mais útil para investigação ou deliberação ou tem maior valor epistêmico que $\beta$ " ${ }^{14}$ Nesse modelo de contração, as crenças que estão mais consolidadas ou são crenças mais básicas ou, como eu prefiro dizer, são crenças que ocupam lugar mais central em nossa teia de crenças, são as crenças que estamos menos preparados para abandonar.

Os seguintes símbolos são usados para formalizar a operação de contração por base consolidada:

$$
\begin{aligned}
& p \leq q: p \text { está no máximo tão consolidada quanto } q . \\
& p<q: p \text { está menos consolidada que } q \text {. }((p \leq q) \wedge \neg(q \leq p))) . \\
& p \equiv q: p \text { e } q \text { estão igualmente consolidadas. }((p \leq q) \wedge(q \leq p)) .
\end{aligned}
$$

\footnotetext{
${ }^{14}$ Nas seções ulteriores deste artigo vou usar a expressão " $p$ é mais básica que $q$ " ou " $p$ tem maior valor epistêmico que $q$ " como sinônimo de " $p$ está mais consolidada que $q$ ". Apenas nesta seção vou usar a última expressão que é uma tradução direta da língua inglesa para expressão usada na lógica da revisão de crenças.
} 

epistêmica:

Seguem cinco postulados padrão para a hierarquia na consolidação

Transitividade: se $p \leq q$ e $q \leq r$, então $p \leq r$.

Dominância: se $p \vdash q$, então $p \leq q$.

Conjuntividade: ou $p \leq(p \wedge q)$ ou $q \leq(p \wedge q)$.

Minimização: se o conjunto de crenças $K$ for consistente, então $p \notin K$ se, e somente se, para todo $q, p \leq q$.

Maximização: se $q \leq p$ para todo $q$, então $p \in \operatorname{Cn}(\varnothing)$.

Uma relação de consolidação (hierárquica) $\leq$ da origem a um operador de - contração por base consolidada de acordo com a seguinte definição:

$q \in K-p$ se, e somente, se $q \in K \wedge(p<(p \vee q) \vee p \in \operatorname{Cn}(\varnothing))$.

Deste modo é demonstrado que a contração por base consolidada coincide exatamente com a contração parcial transitivamente relacional.

\subsubsection{REVISÃO PARCIAL}

O operador de revisão * tem duas tarefas: introduzir uma nova crença $p$ ao conjunto de crenças $K$ e assegurar que o conjunto $K$ ', resultado dessa operação, seja consistente, se $p$ não for uma contradição. A revisão parcial é a operação de revisão no modelo AGM. Como foi dito anteriormente, a revisão pode ser feita através de uma operação de contração e a chamada identidade Levi. Sendo assim, a contração parcial dá origem à revisão parcial.

1) Identidade Levi: $K^{*} \alpha=(K-\neg \alpha)+\alpha$.

A caracterização axiomática do operador de revisão * é então a seguinte: um operador * é um operador de revisão parcial se, e somente se, satisfaz aos seguintes seis postulados:

1) Fechamento: $K^{*} p=\operatorname{Cn}\left(K^{*} p\right)$.

2) Sucesso: $p \in K^{*} p$.

3) Inclusão: $K^{*} p \subseteq K+p$.

4) Vacuidade: se $\neg p \notin \mathrm{K}$, então $K^{*} p=K+p$.

5) Consistência: $K^{*} p$ é consistente se, e somente se, $p$ é consiste.

6) Extensionalidade: se $(p \leftrightarrow q) \in \operatorname{Cn}(\varnothing)$, então $K^{*} p=K^{*} q$.

Estes são os chamados postulados básicos da revisão no modelo AGM. Aos quais devem ser adicionados os seguintes dois postulados suplementares:

7) Superexpansão: $K^{*}(p \& q) \subseteq\left(K^{*} p\right)+q$.

8) Subexpansão: se $\neg q \notin \operatorname{Cn}\left(K^{*} p\right)$, então $\left(K^{*} p\right)+q \subseteq K^{*}(p \& q)$. 
Então * satisfaz a superexpansão se, e somente se, - satisfaz a sobreposição conjuntiva. E * satisfaz a subexpansão se, e somente se, - satisfaz a inclusão conjuntiva.

Esses são, portanto, os postulados axiomáticos da operação de revisão em conjuntos de crenças no modelo AGM. Onde * é o operador de revisão parcial transitivamente relacional se, e somente se, satisfaz aos postulados de 1) a 8).

\subsection{Princí́pio qualitativo}

Após esses desenvolvimentos das ferramentas da lógica de revisão de crenças, podemos voltar-nos para a solução do problema deste artigo. A solução que será proposta tem dois princípios básicos: o princípio quantitativo e o princípio qualitativo. Nessa subseção apresento o princípio qualitativo.

O princípio qualitativo leva em consideração os aspectos qualitativos das crenças. Por aspectos qualitativos quero dizer algo próximo à força de uma determinada crença para um determinado agente. De modo mais preciso, o valor epistêmico que uma determinada crença $p$ tem em um conjunto de crenças $K$ comparada às outras crenças deste sistema. Intuitivamente é a certeza ou a convicção de uma determinada pessoa acerca de uma determinada crença ou o quanto uma pessoa está disposta a abandonar uma crença $p$ comparada a outras crenças que tem. Por exemplo, a crença em Deus de um teísta é uma crença que geralmente tem o status de certeza ou, pelo menos, é uma crença para a qual o teísta dedica grande convicção e, geralmente, não está disposto a abrir mão. É, assim, uma crença forte para o teísta ou de grande valor epistêmico. Para o mesmo teísta, a crença que a democracia é a melhor forma de governo é mais fraca em comparação à crença em Deus. A crença acerca da democracia não tem o status de certeza ou não é algo de que se tem grande convicção. Sempre temos que ter em mente que a força ou o valor epistêmico das crenças, assim como a plausibilidade, é relativo aos agentes. Portanto, a crença em Deus pode ser mais fraca que a crença acerca da democracia para uma determinada pessoa e mais forte para outra.

Está pressuposto na explicação do aspecto qualitativo que, assim como na contração por base consolidada, há algum tipo de hierarquia de crenças. Algumas crenças são mais centrais à nossa teia de crenças (ou estados de crenças) que outras. A crença em Deus para o teísta ocupa lugar central na sua teia de crenças ao passo que a crença acerca da democracia ocupa lugar mais marginal. De modo mais preciso, uma crença $p$ (crença em Deus) pode ocupar um lugar mais central que $q$ (crença acerca da democracia) em conjunto de crenças $K$, nesse caso, $q<p$ no conjunto de crenças $K$. Num conjunto de crenças $K^{\prime}$ essa relação pode se inverter, nesse caso, $p<q$ no conjunto de crenças $K{ }^{\text {, }}{ }^{15}$

\footnotetext{
${ }^{15}$ É importante notar que na expressão "conjuntos de crenças" não existe a relação de hierarquia entre crenças que aparentemente está pressuposta na expressão "teia de crenças". Em "conjuntos de crenças" a relação de hierarquia de crenças aparece apenas se admitirmos a hierarquia em bases consolidadas.
} 
Outro pressuposto é que há certa relação lógica (ou conceitual) entre nossas crenças formando uma teia, isto é, $K \subseteq C n(K)$. Assim, quanto mais central é uma determinada crença $p$, com mais crenças ela se relaciona e tem maior número de implicações. Vejamos o gráfico da Figura 3 que ilustra essa estrutura:

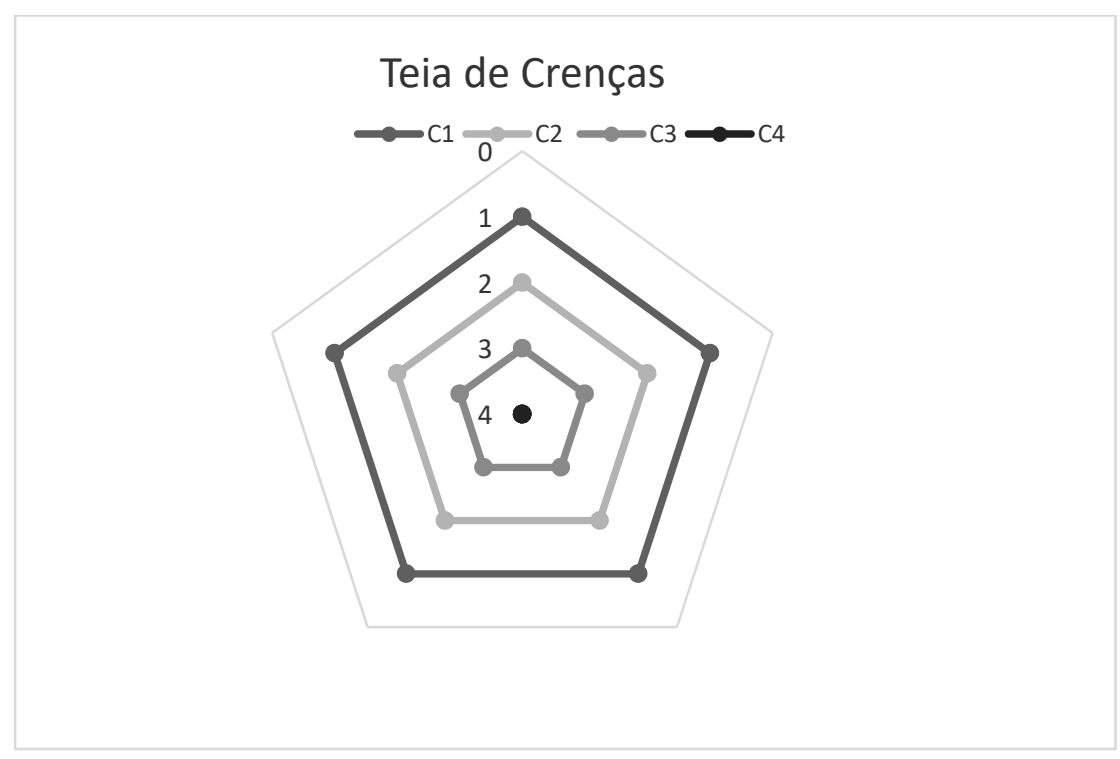

Figura 3

As crenças que ocupam a área $\mathrm{C}_{4}$ no gráfico são as crenças de maior valor epistêmico e com maior número de implicações para as outras crenças do conjunto. Isso quer dizer que as crenças que ocupam essa área são as crenças que estamos menos dispostos a abandonar. Portanto, para abrirmos mão dessas crenças precisamos de fortes razões. ${ }^{16}$ As crenças que, num conjunto de crenças $K$, ocupam a área $\mathrm{C}_{4}$ são as crenças que se abandonadas provocam maior abalo em $K{ }^{17}$ Nesse sentido, uma crença $p$ que ocupa lugar $\mathrm{C}_{4} \mathrm{em} K$ tem um conjunto $C n(p)$ maior que o conjunto $C n(q)$ de uma crença $q$ que ocupa lugar $\mathrm{C}_{1}$ em $K$.

A tabela de regras que proponho para a mudança de crenças forçada por argumentos e estrutura de teia de crenças é ilustrada no gráfico da Figura 4.:

\footnotetext{
${ }^{16}$ Não quero me comprometer com a ideia de que este gráfico esgote as possibilidades de forças de crenças, sendo assim, ele deve ser encarado como um modelo para representar a hierarquia das crenças.

${ }^{17}$ Vale lembrar que um dos princípios mais básicos do modelo AGM sugere que qualquer mudança em um conjunto de crenças deve sempre se limitar ao mínimo necessário para acomodar a operação.
} 


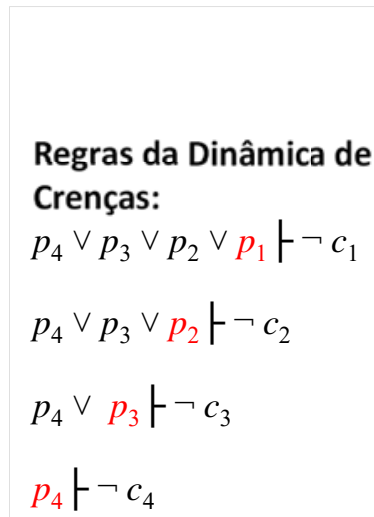

\section{Regra Geral:}

Teia de Crenças

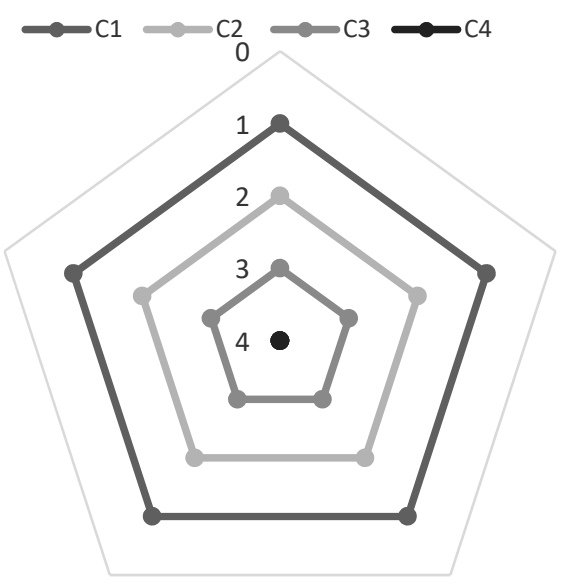

Figura 4

Os seguintes três casos análogos à contração por base consolidada devem ser explicados pelas regras da dinâmica de crenças via argumentos:

$c \leq p: c$ tem menor ou igual valor epistêmico $p$.

$c<p$ : $c$ tem menor valor epistêmico que $p$.

$c \equiv p: c$ e $p$ tem mesmo valor epistêmico.

No caso onde a crença que é inconsistente com um argumento tem menor valor epistêmico que as premissas do argumento $(c<p)$, o argumento nos obriga a refutar ou aceitar a conclusão. Ou seja, estamos obrigados a refutar o argumento ou a revisar nossas crenças para eliminar a inconsistência e acomodar a conclusão a que o argumento conduz. No caso onde as premissas têm o mesmo valor epistêmico ou menor valor epistêmico que a crenças em causa $(c \equiv p) \vee(c \leq p)$ : uma restrição adicional deve ser levada em consideração: o argumento deve dar conta de explicar a ilusão da crença em $c^{18}$

Alguns exemplos de aplicação mais direta devem ajudar na compreensão do que está em causa aqui. As regras para revisão de crenças afirmam que perante um argumento que a sua conclusão implique que uma crença qualquer $c$ com força $C_{3}$ seja falsa deve apelar para premissas que tenham força $p_{4}$ ou $p_{3} .\left(p_{4} \mathbf{v} p_{3}\right.$ F $\neg c)$. Caso as premissas tenham apenas força $p_{3}$, uma restrição adicional deve ser levada em consideração; o argumento deve dar conta de explicar a ilusão da crença em $C$. (Representado no gráfico $\left.p_{4} \mathbf{v} p_{3} \vdash \neg c_{3}\right) .{ }^{19} \mathrm{O}$ mesmo deve ser considerado para cada nível de força de crenças sempre seguindo as regras que aparecem no

${ }^{18}$ É bom lembrar que estamos tratando de argumentos plausíveis argumentativamente, portanto, não há necessidade de falar aqui dos casos em que as premissas têm menor valor epistêmico que as crenças em causa. Estes são, certamente, casos de argumentos implausíveis argumentativamente. Veja página 14 deste artigo.

${ }^{19} p_{3}$ aparece marcado de vermelho porque tem a restrição adicional mencionada. 
gráfico. As crenças variam de força de $\mathrm{C}_{4}$, as centrais e com maior valor epistêmico, a $\mathrm{C}_{1}$, as marginais e com menor valor epistêmico. Não temos grandes problemas em abandonar crenças que ocupem a área $c_{1}$ em nosso conjunto de crenças, sendo assim, não precisamos de razões muito fortes para fazê-lo. Em contrapartida, não estamos, geralmente, dispostos a trocar crenças que ocupem a área $\mathrm{C}_{4}$. Para trocar crenças que ocupam esta área precisamos de motivos realmente muito bons e esses motivos têm que dar conta de explicar a ilusão na crença $\mathrm{C}_{4}$. Para um argumento ser uma boa razão para revisar nosso conjunto de crenças deve satisfazer as regras da dinâmica de crenças apresentadas.

Assim o argumento cético que apresentei no início deste artigo não é uma boa razão para reformar a nosso conjunto de crenças. $O$ argumento não recorre a premissas com força adequada - as premissas são muito mais fracas que a crença que o argumento pretende negar - e não dá conta de explicar a ilusão em acreditar na existência de uma mão que digita este artigo.

\subsection{PrincíPIO QUANIITATIVO}

O princípio quantitativo leva em consideração os aspectos quantitativos da dinâmica de crenças. O leitor deve ter se sentido desconfortável com a descrição do princípio qualitativo; é muito simples e nossa dinâmica de reforma de crenças é bastante mais complexa que a descrição feita. Se essa foi a sensação, está correta. De fato, a maneira como trocamos, damos adesão e rejeitamos crenças é bastante mais complexa que a descrição feita até o momento. Nesta e nas próximas seções veremos como a dinâmica de crenças é, de fato, bastante complexa.

Enquanto na seção anterior vimos o princípio que leva em consideração a força de uma crença particular $c$ perante um argumento, veremos agora como um conjunto vasto de premissas $P$ pode colocar uma crença $c$ em risco. Vimos que para um argumento forçar a aceitação de uma conclusão que colida com uma crença prévia, as premissas têm que ter força proporcional à crença que está em causa. Se isso acontecer, o interlocutor está forçado a refutar o argumento ou a aceitar a conclusão. No caso de aceitar a conclusão deve revisar seu conjunto de crenças prévio $K$, dando origem a um novo conjunto de crenças $K^{\prime}$ consistente com a nova crença. Porém, será esta a única maneira de um argumento forçar a revisão de crenças? Parece que a resposta a essa pergunta é negativa. Imagine um caso em que um argumento recorre, ao invés de premissas com força adequada para articular o argumento, a um número vasto de premissas que colidam com a crença em causa. Neste caso parece que o argumento, tal como no caso de premissas com força adequada, pode forçar o abandono, a pena de irracionalidade, da crença relevante. Explicando melhor essa ideia: suponhamos uma crença de força $\mathrm{C}_{2}$ para alguém. Para forçar, via princípio quantitativo, o abandono dessa crença, temos que lançar mão no argumento de um número vasto de premissas (crenças que fazem parte do conjunto de crenças do agente relevante) que colidam com a crença em causa. Assim, mesmo que as premissas não tenham individualmente força adequada para fazer o argumento ser bom, o fazem por outra via, a quantitativa. Nesse caso o argumento também provoca, por via 
quantitativa, grande abalo em nosso conjunto de crenças anteriores $K$, resultando em um conjunto $K^{\prime}$ após a revisão.

Através do princípio quantitativo temos mais um motivo para não aceitar a conclusão a que o argumento cético conduz. Se ele funcionasse, implicaria que, além de minha crença na existência do mundo exterior ser falsa - crença de força $\mathrm{C}_{4}$ para a maioria dos agentes -, um número vastíssimo de crenças seria falso. $\mathrm{O}$ café que tomei pela tarde pode não estar sendo digerido da maneira que pensava. O notebook que estou escrevendo este artigo pode não existir. Os dedos que uso para digitar este artigo podem não ser reais. E assim por diante, até quase todas as minhas crenças serem postas em causa. O argumento cético é inconsistente com um número muito vasto de crenças que fazem parte de $K$, portanto, aceitar a sua conclusão implica em abalar de forma significativa a minha teia de crenças. $O$ argumento cético, além de não satisfazer ao princípio qualitativo, não satisfaz ao princípio quantitativo. ${ }^{20}$

\subsection{PRINCÍPIOS PONDERADOS}

O princípio qualitativo, aparentemente claro e preciso, e o princípio quantitativo, impreciso e vago, devem explicar o problema central deste artigo que características um argumento deve apresentar para obrigar um agente a refutálo ou a aceitá-lo? Agora vou tentar mostrar que os dois princípios estão intimamente ligados e juntos indicam o caminho para responder à pergunta.

O princípio qualitativo é o valor epistêmico ou a força de uma crença para um agente. Por que uma crença tem força diferente de outra crença? Por que uma mesma frase (ou proposição) pode ter forças diferentes para agentes diferentes? A resposta para essas perguntas explicita a relação entre os princípios. A força de uma crença c em um conjunto de crenças $K$ é proporcional ao número de crenças que estão logicamente (ou conceitualmente) ligadas a c em K. Em termos mais óbvios, quanto maior o número de crenças que devem ser abandonadas caso uma dada crença seja abandonada, maior é a força dessa crença dentro desse sistema de crenças. A resposta à primeira pergunta é óbvia: uma crença é mais forte que outra dentro de uma teia porque é mais central ao sistema e tem um número maior de crenças conectadas logicamente (conceitualmente) a ela, ou seja, caso seja abandonada, um número maior de crenças também deve ser abandonada. Respondendo à segunda pergunta: uma crença é mais forte para uma pessoa que para outra porque cada agente forma sua teia de crença de uma forma e pode haver ligações diferentes entre as crenças em cada sistema. Por outras palavras, agente cognitivos diferentes podem ter conjunto de crenças diferentes.

Vemos desse modo que os dois princípios estão intimamente ligados e que o princípio qualitativo é, em última instância, definido em termos quantitativos e que, ao contrário do que possa parecer à primeira vista, tanto o princípio quantitativo quanto o princípio qualitativo não guardam mistério algum e, ao que

20 Estes argumentos não pretendem ser uma refutação do cético. Os ataques direcionados ao argumento cético são apenas ilustrativos e podem ser reformulados em outros exemplos. 
parece, explicam a dinâmica da revisão de crenças. Mas se o princípio qualitativo pode ser definido em termos do princípio quantitativo, por que não eliminamos o primeiro em detrimento do segundo? A resposta para esta pergunta fica para a próxima seção.

À luz das ponderações feitas até aqui podemos reconsiderar o conceito de plausibilidade argumentativa (P.A.). Para isso teremos que distinguir entre argumentos ingênuos - cuja conclusão é consistente com o conjunto de crenças prévias $K$ - e argumentos incisivos - cuja conclusão é inconsistente com $K$.

\section{Argumentos ingênuos}

Um argumento ingênuo é bom se, e somente se, é P.A. ${ }^{21}$

Sendo assim, se estamos perante um argumento ingênuo e plausível argumentativamente, estamos obrigados a refutar o argumento ou a aceitar a conclusão. Se não somos capazes de refutá-lo, temos um bom motivo para expandir nosso conjunto de crenças de modo a acomodar a conclusão a que o argumento conduz. Sendo assim, a operação do modelo AGM para argumentos ingênuos é a expansão $(K+p)$.

\section{Argumentos incisivos}

Um argumento incisivo é bom se, e somente se, é válido ${ }^{(C)}$, as premissas são verdadeiras $^{(C)}$ e o argumento satisfaz ao princípio qualitativo ou quantitativo das regras para dinâmica de crenças.

No caso de argumentos incisivos o argumento deve ser válido ${ }^{(\mathrm{C})}-$ o agente epistêmico deve acreditar que o argumento é válido -, as premissas devem ser verdadeiras $^{(\mathrm{C})}$ - o agente epistêmico deve acreditar que as premissas são verdadeiras - e o argumento deve satisfazer ao princípio qualitativo ou quantitativo das regras para dinâmica de crenças. Satisfazendo a esses pré-requisitos, um argumento incisivo coloca o agente epistêmico em uma situação onde ele é obrigado a refutá-lo ou a aceitá-lo. No caso em que o agente não é capaz de refutálo, deve revisar o seu conjunto de crenças $\mathrm{K}$, de modo a acomodar a conclusão do argumento em um conjunto K' consistente de crenças após a operação. Sendo assim, a operação do modelo AGM para argumentos incisivos é a revisão $(K * p)$ ou, pela identidade Levi, a contração $(K-\neg p)+p$.

Para reconsiderar o conceito de P.A. temos a seguinte definição:

Um argumento é P.A. se, e somente se, é um argumento bom.

Com base nessa reconsideração do conceito de P.A.: se o argumento for P.A., ou seja, se satisfazer a um dos dois casos de argumento bom, o agente relevante está epistemicamente obrigado a refutar o argumento ou a aceitar a

\footnotetext{
21 "Argumento bom" quer dizer apenas "argumento que obriga o agente epistêmico a refutá-lo ou a aceitá-lo".
} 
conclusão a que o argumento conduz. Caso seja incapaz de refutar, deve seguir uma das operações do modelo AGM para revisão em conjuntos de crenças.

\section{FALIBILIDADE}

Apesar de quase não ter mencionado a falibilidade dos agentes ao longo deste artigo, ela esteve sempre como pano de fundo em todos os argumentos e critérios formulados até aqui. A ideia foi formular critérios que, como disse anteriormente, fossem generosos com agentes epistemicamente limitados e falíveis e, ainda assim, preservassem a virtude epistêmica da prática argumentativa. Como Locke defende, a nossa incapacidade em mostrar o que há de errado em um argumento não prova que o argumento seja bom:

Não é prova que outro homem está no caminho correto, nem que eu deva tomar o mesmo caminho que ele, que eu não conheça um melhor. 3. Também não é prova que outro homem está no caminho correto porque ele mostrou que eu estou errado. [...] Eu posso ser ignorante e não ser capaz de apresentar um melhor: eu posso me encontrar em erro e outra pessoa pode vir a me mostra isso ${ }^{22}$ (LOCKE, 1975, Livro IV, Capítulo XVII, seção 20).

Aqui destaco os dois aspectos que penso que são os mais relevantes relacionados com a falibilidade dos agentes: a falibilidade lógica e a suspensão temporária de juízo.

\subsection{OMNISCIÊNCIA LÓGICA}

Uma pessoa que aceita as normas tal como acabo de formular e pretende agir de forma epistemicamente virtuosa frente a argumentos vai sempre saber em que circunstância está obrigada a refutar ou aceitar um argumento? Dificilmente! Somos falíveis e muitas vezes incapazes de saber quais são as consequências de nossas crenças e quais são as relações lógicas entre elas. Provavelmente, dentro do nosso sistema de crenças há crenças incompatíveis entre si e nem nos damos conta. Sendo assim, a falibilidade, ou a falsidade da nossa omnisciência lógica, ocupa lugar central na discussão acerca da plausibilidade argumentativa e das normas epistêmicas que regulam a revisão de crenças forçada por argumentos. A força dos critérios para os argumentos P.A. está exatamente ligada ao fato de sermos falíveis. A partir do momento que reconhecemos nossa falibilidade e admitimos a possibilidade de não termos domínio completo sobre todas as nossas crenças e suas relações lógicas, vemos que os critérios exigidos para colocar um agente numa situação de refutar ou aceitar têm que ser mais fortes que a cogência

22 Tradução de responsabilidade deste autor. 
como tipicamente entendida; um conceito como plausibilidade argumentativa é mais adequado.

Além de termos que considerar o conjunto prévio de crenças do agente relevante, temos que lhe conceder, em nossas normas, a possibilidade de não se dar conta de todas as implicações de suas crenças. E se admitimos que o agente não dá conta de todas as crenças que estão acomodadas em seu sistema de crenças, então as normas reguladoras das situações onde uma nova crença é imposta via argumento têm que ser ainda mais caridosa com o agente. Certamente, agentes falíveis não são capazes de ver todas as implicações da nova crença e, menos ainda, todas as relações que essa nova crença tem com as crenças que já estão acomodas em seu conjunto de crenças.

Por que não eliminamos o princípio qualitativo das crenças em detrimento do princípio quantitativo, dado que o primeiro pode ser definido em termos do segundo? Não eliminamos um princípio em detrimento ao outro porque somos falíveis e limitados cognitivamente. Não podemos ver imediatamente quantas crenças estão ligadas logicamente a uma crença que está em causa perante um argumento. Além disso, não sabemos quais serão as possíveis conexões de crenças que o abandono de uma determinada crença implicará e não sabemos como a nova crença vai se conectar às outras que já estão acomodas no sistema. Logo, por sermos falíveis e limitados cognitivamente, temos que manter os dois princípios. Se não fossemos falíveis e limitados cognitivamente, saberíamos, perante um argumento, todas as implicações da aceitação da sua conclusão para nossa teia de crenças. Assim, apenas o princípio quantitativo seria suficiente como norma para aceitação de argumentos. Dada a nossa falibilidade e limitação cognitiva, o princípio qualitativo faz-se necessário.

\subsection{SUSPENSÃo IEMPORÁRIA DE JUÍZO}

O leitor talvez tenha ficado com a sensação de que a reflexão que conduzi neste artigo foi demasiadamente idealizada com aplicação apenas a casos em recortes contextuais muito precisos e distantes da realidade da prática da argumentativa do dia-a-dia. Falei até agora apenas das características que um argumento deve apresentar para nos colocar numa situação que estamos obrigados a refutar ou a aceitar: Mas essas duas possibilidades, certamente, não são as únicas. A suspensão do juízo é a terceira possibilidade lógica e, alguns casos, é uma ação legítima. Se pensarmos bem, não saímos por aí trocando crenças ou refutando argumentos o tempo todo. Na verdade, o que geralmente fazemos é suspender juízos frente a grande quantidade de nova informação a que somos expostos - que muitas vezes aparecem em forma de argumentos. Sendo assim, a suspensão de juízo deve ser uma ação legítima na epistemologia da prática argumentativa.

O tempo é elemento central quando pensamos na suspensão do juízo. Quando estamos perante um argumento cuja conclusão colida fortemente com nosso sistema de crenças e somos incapazes de refutar o argumento, suspender o juízo parece uma saída legítima. Mas a suspensão do juízo não deve ser encarada como uma fuga fácil de argumentos convincentes, ao contrário, deve ser encarada 
como uma possibilidade para agente que se encontra perante um argumento que seja incapaz de refutar de se dedicar a estudar, pesquisar com cuidado, se ater a pormenores do argumento para, por fim, tentar refutar o argumento. Se depois de feito isso o agente ainda assim for incapaz de refutar o argumento, restar-lhe-á apenas a possibilidade de aceitar a conclusão a que o argumento conduz. Portanto, a fuga ao terreno seguro dos indecisos não é tão segura assim. Ao término de um determinado tempo, uma posição entre refutar ou aceitar deve ser tomada quando somos colocados frente a argumentos que nos parecem convincentes. A suspensão de juízo é, então, uma ação temporariamente legítima, não um lugar seguro e cômodo para escapar de argumentos convincentes.

\section{O REALISMO INDIRETO}

Ainda há algo de importante a se explicar após a exposição feita até aqui e o leitor provavelmente tem alguma das objeções a seguir em mente: como podemos aceitar os critérios formulados se os elementos metafísicos que garantem a conexão das crenças com a realidade foram preteridos? Se os critérios a serem satisfeitos pelos argumentos são meramente epistêmicos, como podemos garantir que eles funcionem para descobrir verdades? Afinal, parece que tudo o que queremos com critérios para argumentos é que esses aumentem as nossas chances de aceitar crenças verdadeiras de modo a ampliar o número de crenças verdadeiras em nosso conjunto de crenças. E, idealmente, chegar ao ponto de preservar apenas crenças verdadeiras eliminando todas as crenças falsas do nosso conjunto de crenças. Mesmo que o leitor tenha a intuição, assim como eu, que os elementos metafísicos envolvidos no conceito de cogência sejam demasiadamente fortes ou obscuros e que pense que não devam ser exigidos de argumentos, certamente não vai querer se submeter a critérios que não sirvam para aumentar as chances de aceitar verdades. Se o que queremos é, no fim de tudo, aumentar o número de verdades em nosso conjunto de crenças, algum elemento metafísico é imprescindivel. Portanto, uma teoria da argumentação que elimine completamente os elementos metafísicos dos critérios que estipulam quais são as características que os argumentos bons devem apresentar perde a sua motivação principal e deve, apenas por isso, ao que parece, ser rejeitada.

Um possível contraexemplo que tem como pano de fundo as ideias apresentadas acima é o seguinte: suponhamos uma pessoa que tem um conjunto massivamente falso de crenças. Para essa pessoa seria natural que muitos argumentos apresentassem conclusões que fossem inconsistentes com seu

conjunto de crenças. É plausível supor ainda que seu conjunto de crenças falsas tivesse uma coerência interna tal que dificilmente os argumentos que lhe fossem apresentados teria mais força que as suas crenças. Nesse caso a pessoa estaria racionalmente preservando crenças falsas em seu conjunto de crenças. Este parece ser um resultado que deve ser evitado de alguma forma ou explicado pela teoria.

Nesta seção apresento rapidamente uma possível resposta a essa objeção, mostrando como a teoria da argumentação que proponho tem um elemento metafísico importante que preserva a intenção de expandir ao máximo o número 
de crenças verdadeiras dentro da nossa teia de crenças e indica um caminho para escapar ao contraexemplo apresentado.

A sugestão é um tipo de realismo indireto que passo apresentar em linhas gerais agora. Ao invés dos elementos metafísicos da cogência (validade e verdade) temos que ter outro elemento que possa resolver o problema, mas que não seja o mesmo que esses elementos. A sugestão não é exigir conexão entre uma premissa ou uma forma argumentativa e a validade, mas, ao invés disso, exigir uma interação dinâmica entre o conjunto de crenças de um agente e a realidade. Não quero dizer que todas as crenças de um agente devam ser verdadeiras, mas também não é plausível pensar em um agente racional - pelos mesmos critérios propostos aqui - que mantenha em um conjunto de crenças massivamente falso. Há na verdade uma interface dinâmica de abandono, adesão e revisão de crenças frente às informações que vem da realidade, seja por meio da percepção, do testemunho, da argumentação ou de outras formas que talvez possamos imaginar.

A ideia então não é refutar ao contraexemplo mencionado, mas tentar evitálo, dizendo que é bastante implausível pensar em uma pessoa racional que preserva um conjunto massivamente falso de crenças frente às informações fornecidas pela realidade o tempo todo. Por outras palavras, é difícil pensar em um agente racional que, inserido na realidade e o tempo todo em contato com ela tendo que colocar crenças em causa, possa preservar crenças massivamente falsas em seu conjunto de crenças. $^{23}$ Mais uma vez a falibilidade é importante aqui. Admitimos que temos crenças falsas em nossos conjuntos de crenças e colocamolas a prova o tempo todo seguindo regras de racionalidade e, desse modo, tendemos a cada vez aumentar a quantidade de crenças verdadeiras e diminuir a quantidade de crenças falsas. Essa ideia é enriquecida pelo choque entre conjuntos de crenças de vários agentes de modo a adiantar esse processo e fazer da prática argumentativa algo essencial à nossa economia cognitiva principalmente em contextos onde as dúvidas, por vezes, são muitas como, por exemplo, na prática da filosofia e das ciências.

Talvez esta solução não seja suficientemente convincente, mas penso que capta bastante da forma como trocamos crenças e aumentamos - principalmente todos juntos - a quantidade de crenças verdadeiras e nosso conhecimento acerca da realidade. Claro que para o cético e para quem a expressão "aumentar conhecimento" não faz sentido o que acabo de defender é o mesmo que nada, mas para os demais imagino que essas sugestões serão bem-vindas.

\section{CONCLUSÃO}

Para concluir, se os argumentos apresentados ao longo deste artigo funcionarem e se os princípios qualitativo e quantitativo forem suficientes, temos critérios que preservam a condicional do problema - se estamos perante um

${ }^{23}$ É importante notar que não estou defendo que seja implausível pensar em um agente irracional que preserva um conjunto de crenças massivamente falsas, penso apenas que para um agente racional isto parece bastante implausível. 
argumento P.A., temos a obrigação epistêmica de refutar o argumento ou aceitar a conclusão a que ele conduz - e o conceito de cogência é supérfluo como norma epistêmica. A ideia deste artigo, então, era manter a condicional como uma norma epistêmica básica e atacar o conceito de cogência tal como comumente entendido. Mostrar que o conceito tal como formulado não é suficiente e nem necessário para dizer sob quais circunstâncias estamos obrigados a refutar ou a aceitar.

Como resultado indireto deste artigo temos ainda mais armas para lidar com os argumentos céticos, porque certamente eles não satisfazem tanto ao princípio qualitativo quanto ao princípio quantitativo. Se aceitarmos que os princípios captam algo de fundamental acerca da plausibilidade argumentativa para argumentos incisivos, podemos afirmar que os argumentos céticos são típicos argumentos implausíveis argumentativamente e, por isso, não estamos obrigados a refutar ou aceitar esses argumentos.

\section{REFERÊNCIAS BIBLIOGRÁFICAS}

ADLER, Jonathan. Resisting the force of argument. The Journal of Philosophy, v. 106, n. 6, p. 339-364, 2009.

ALCHOURRON, Carlos; GÄRDENFORS, Peter; MAKINSON, David. On the logic of theory change: partial meet contraction and revision functions. Journal of Symbolic Logic, v. 50, n. 2, p. 510-530, 1985.

HANSSON, Sven. Logic of belief revision. In: ZALTA, Edward (ed.). The Stanford Encyclopedia of Philosophy, 2009. Disponivel em: http://plato.stanford.edu/entries/logic-belief-revision/\#ParMeeCon. Acesso em: 10 jul. 2011.

HUME, David. Investigações sobre o entendimento humano e sobre os princípios da moral. Trad. de Jose Oscar de Almeida Marques. São Paulo: Editora UNESP, 2004 .

LEVI, Isaac. Subjunctives, dispositions and chances. Synthese, v. 34, n. 4, p. 423455, 1977.

The fixation of belief and its undoing. Cambridge, MA: Cambridge University Press, 1991.

LOCKE, John. An essay concerning Human Understanding. New York: Oxford: Nidditch, P.H., 1975.

MURCHO, Desidério. Epistemologia da argumentação. In: . Pensar outra vez: Filosofia, valor e verdade. Vila Nova de Famalicão: Edições Quasi, 2006. p. 113-129.

PUTNAM, Hilary. Brains in a vat. In: Reason, Truth and History. Cambridge: Cambridge University Press, 1981. p. 1-22. 


\section{AGRADECIMENTOS}

Estou em débito com o professor Jonathan E. Adler (in memoriam) e com professor Desidério Murcho, além dos colegas Gabriel Primo e Ulisses Viana. Agradeço à audiência dos seguintes eventos: Seminário Permanente de Filosofia da UFOP, IV Encontro Nacional de Pesquisa em Filosofia da UFOP, II Congresso da Sociedade Brasileira de Filosofia Analítica e LanCog Seminar. Agradeço também à Gabrielle Ramos, Renan Andrade e Moara Furtado que fizeram o favor de ler as primeiras versões deste artigo. Agradeço também ao apoio da CAPES e do CNPq. 